\title{
Motivators, barriers and incidence of screening for celiac disease in first degree relatives at 14 years after initial screening
}

\author{
Anne R Lee ${ }^{1 *}$, Shari Keats ${ }^{2}$, Randi L Wolf ${ }^{2}$, Benjamin Lebwohl ${ }^{1}$, Edward J Ciaccio ${ }^{1}$ and Peter HR Green ${ }^{1}$ \\ ${ }^{1}$ Celiac Disease Center, Columbia University Irving Medical Center, Harkness Pavilion, New York, NY 10032, USA \\ ${ }^{2}$ Department of Health \& Behavior Studies, Program in Nutrition, Teachers College, Columbia University, New York, NY 10027, USA
}

\begin{abstract}
Background: The prevalence of celiac disease (CD) is nearly $1 \%$ of the general population, but higher among first-degree relatives. Current guidelines recommend testing for symptomatic first-degree relatives and consideration of testing for asymptomatic first-degree relatives. We sought to determine incidence of follow-up testing, as well as facilitators and barriers, in first-degree relatives who participated in a Family Screening Day 2005.
\end{abstract}

Method: The 272 first-degree relatives who provided initial contact information were invited to participate in this study. A self-administered questionnaire queried retesting, conversion, additional diagnosis, and relationship to the index family member. Data was analyzed using descriptive statistics.

Results: Responses ( $n=34,13 \%$ of the originally screened cohort) were received, 17 participants met inclusion criteria and completed the survey. The participants were predominately female (71\%) and between the ages of 26-55 (59\%) at follow-up. Thirteen (77\%) of the 17 participants tested negative in 2005. The majority ( $\mathrm{N}=9$, $69 \%)$ of those initially testing negative had not been retested nearly 14 years later. Barriers to retesting were the belief that retesting was not necessary (78\%) and lack of symptoms (22\%). Presence of symptoms were a motivating factor for the 3 of the four individuals who did retest (75\%).

Conclusion: We found a low rate of retesting of first-degree relatives despite recommendations. In the light of increased incidence of celiac disease in first-degree relatives, as well as the increased risk of developing comorbidities if celiac disease is left untreated, the results of this study indicate the need for increased awareness of testing recommendations among first-degree relatives.

\section{Introduction}

Celiac disease $(\mathrm{CD})$ is a genetically mediated autoimmune disease [1]. Ingestion of gluten results in damage to the small intestine [1,2]. The classic gastrointestinal symptoms of CD including diarrhea, weight loss, and abdominal discomfort, are less frequently seen in adults [3]. Lo's (2003) study reported usual modes of adult presentation of celiac disease as symptoms (62\%), anemia (15\%), bone loss (15\%) and screening of first-degree relatives (13\%). Presentation with diarrhea decreased from $73 \%$ to $43 \%$ in patients diagnosed before 1993 [3]. Adults often present with atypical or extra-intestinal symptoms of migraines, joint pain, fatigue, and infertility. One study reviewing celiac disease diagnosis reported an increased presentation of nonclassical symptoms from $14.8 \%$ prior to 1985 to $51.6 \%$ in 2010 [4]. Undiagnosed CD is associated with increased risk of Type 1 diabetes, osteoporosis, thyroid disease, additional autoimmune diseases, and potentially gastrointestinal cancers [5,6]. Missed or delayed diagnosis, especially in individuals who have non-classical presentation or are asymptomatic, could lead to additional health risks.

The specific genetic alleles HLA-DQ2 and HLA-DQ8 are present in $30-40 \%$ of the general population [7]. While the prevalence of CD is nearly $1 \%$ of the general population $[8,9]$, there is an increased risk of CD (5 to 10\%) in first-degree relatives (parent, sibling, offspring) [10]. Recent studies have reported that the conversion rate of first-degree relatives from seronegative to seropositive is between 1.6 and $6.6 \%$ over a 0.5 to 20 -year time period $[10,11]$. The mode of presentation among family members is usually not the classic gastrointestinal symptoms. Fifty percent of first-degree relatives present with extra-intestinal or atypical symptoms of CD or are asymptomatic $[12,13]$.

Multiple professional guidelines recommend that first-degree relatives be tested if they show possible signs or symptoms of CD, and that testing should be considered for asymptomatic first-degree relatives [14-16]. However, several studies have shown a high degree of untested family members [10,17-19]. In the study by Roy and colleagues, it was found that only $44 \%$ of non-University physicians (those in private practice or not associated with an academic or university hospital) of established CD patients recommended that family members be tested [17]. In a review of medical records of patients with biopsy proven celiac disease, Faye and colleagues [18] found that $30 \%$ of symptomatic first-degree relatives were not tested for CD. Two other studies sought to test first-degree relatives to determine incidence and found rates of CD between $12-14 \%$ [20,21]. In both studies, majority of patients

${ }^{\star}$ Correspondence to: Anne R Lee, Celiac Disease Center, Columbia University Irving Medical Center, Harkness Pavilion, 180 Fort Washington Avenue, New York, NY, USA, Tel: (212) 305-5590; E-mail: arl2004@cumc.columbia.edu

Key words: celiac disease, family screening day, seropositive, healthcare professionals

Received: March 04, 2019; Accepted: March 19, 2019; Published: March 22, 2019 
diagnosed with $\mathrm{CD}$ from screening the index patient did not have typical gastrointestinal symptoms $[20,21]$.

Due to the increased risk of developing CD among family members, this study sought to query a population of families who participated in a screening study at the Celiac Disease Center at Columbia University Medical Center in New York 14 years prior to this study. The study investigated the rate of re-testing, motivators and barriers to testing, as well as the conversion from seronegative to seropositive amongst first-degree relatives.

\section{Methods}

The Celiac Disease Center at Columbia University Medical Center (The Celiac Center) conducted a Family Screening Day in April 2005, where family members of patients at the center, and the general public were invited to have blood testing (IgA, tTGA, and EMA) for evidence of $\mathrm{CD}$. At that time, participants signed forms consenting to be contacted for future research. These individuals served as our potential pool of study participants.

In February 2018, 272 participants were identified and invited via their email address we had from the screening day, to participate in a follow-up study using a self-administered questionnaire. The eligibility requirements were: 1 . family member with $C D$ and 2 . granted consent for follow-up. If the individual was willing to participate in the current study, they were instructed to follow an Internet link to a survey provided in the recruitment email. In cases where multiple family members shared a common email address, one email was sent to each of the family members requesting that each individual complete a survey. Individuals with duplicate and invalid email addresses were contacted via telephone, and a current email address was requested. Individuals could choose not to participate in the survey or could provide an updated email address.

The survey was constructed using Qualtrics, a web-based questionnaire service (https://www.qualtrics.com). After reviewing the study description and the informed consent, participants had the option of terminating the survey or continuing. Questions included demographics and health characteristics, results of Family Screening Day testing (e.g., positive for $\mathrm{CD}$, negative for $\mathrm{CD}$, do not remember), and, depending on their response to testing results, a series of followup questions. The survey queried if the participant pursued follow-up testing for $\mathrm{CD}$, and if so, the result of their testing, any symptoms, the number of follow-up tests, perceived motivating factors or barriers to testing, and other interactions with healthcare professionals to discuss CD. Data was analyzed using descriptive statistics. Approval for this study was granted from both Columbia University Medical Center and Teachers College, Columbia University Institutional Review and Ethics Boards.

\section{Results}

A total of 272 eligible participants were identified. A total of 173 emails were sent after removing the 99 duplicates. After excluding those with invalid email addresses and/or invalid phone numbers, 101 possible participants received the email. A total of 34 began the survey and 30 completed it. Among them, 17 surveys were included and used for analysis. The other 13 (of the 30 completed) were excluded either because they reported not being a family member of an index CD patient or because they were the index CD patient themselves (Figure 1). Overall, the response rate for the study using all eligible participants $(\mathrm{N}=272)$ for completed surveys was $11 \%(30 / 272)$. However, when using only valid participants among the viable contacts, the overall response rate was $17 \%(17 / 101)$.

Characteristics of the participants are shown in table 1 . They were predominately female (71\%), between the ages of $26-55$ (59\%), had annual household incomes over $\$ 100,000$ (53\%), and had private health insurance and/or Medicare (88\%). Almost one quarter (24\%) had another autoimmune disease (e.g., thyroid, lupus, Sjogrens's) in addition to celiac disease.

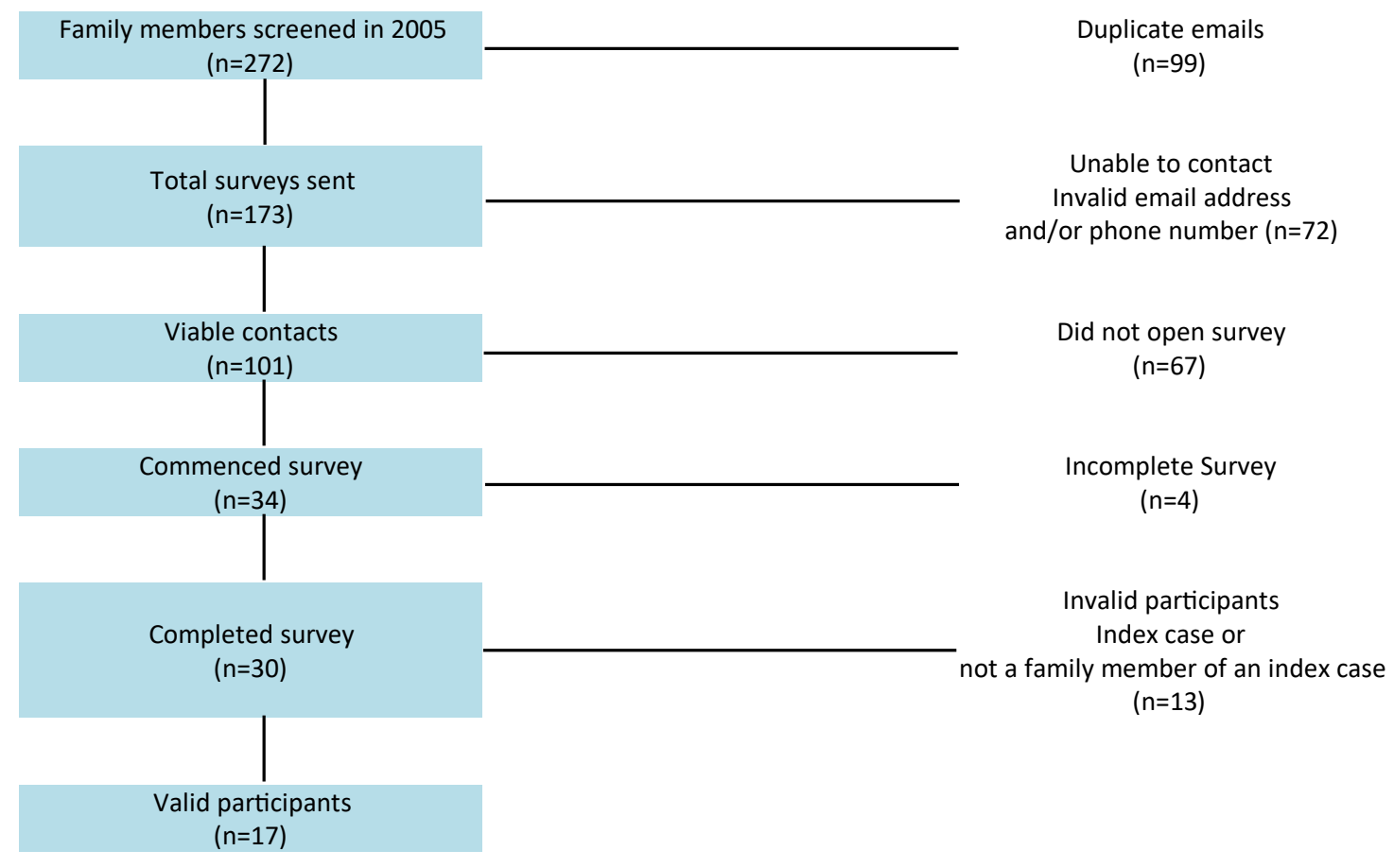

Figure 1. Flowchart of participants. 


\begin{tabular}{|c|c|c|c|}
\hline & \multirow[b]{2}{*}{ Participants } & \multicolumn{2}{|c|}{$\begin{array}{l}\text { Participants that Initially Tested Negative at Family Screening Day } \\
\text { in } 2005\end{array}$} \\
\hline & & Retested & Not Retested \\
\hline & $(\mathrm{n}=17) \mathrm{N}(\%)$ & $(\mathrm{n}=4) \mathrm{N}(\%)$ & $(\mathrm{n}=9) \mathrm{N}(\%)$ \\
\hline \multicolumn{4}{|l|}{ Gender } \\
\hline Male & $5(29 \%)$ & $0(0 \%)$ & $5(56 \%)$ \\
\hline Female & $12(71 \%)$ & $4(100 \%)$ & $4(44 \%)$ \\
\hline \multicolumn{4}{|l|}{ Age } \\
\hline $19-25$ & $0(0 \%)$ & $0(0 \%)$ & $0(0 \%)$ \\
\hline $26-55$ & $10(59 \%)$ & $4(100 \%)$ & $2(22 \%)$ \\
\hline $56+$ & $7(41 \%)$ & $0(0 \%)$ & $7(78 \%)$ \\
\hline \multicolumn{4}{|l|}{ Annual Household Income } \\
\hline$\$ 25,000$ to $\$ 50,000$ & $2(12 \%)$ & $1(25 \%)$ & $0(0 \%)$ \\
\hline$\$ 50,001$ to $\$ 100,000$ & $2(12 \%)$ & $0(0 \%)$ & $2(22 \%)$ \\
\hline Over $\$ 100,000$ & $9(53 \%)$ & $3(75 \%)$ & $4(44 \%)$ \\
\hline Prefer not to disclose & $4(23 \%)$ & $0(0 \%)$ & $3(33 \%)$ \\
\hline \multicolumn{4}{|l|}{ Insurance } \\
\hline $\begin{array}{l}\text { Medicaid or other government sponsored health insurance coverage for } \\
\text { low-income individuals/families including Affordable Care }\end{array}$ & $2(12 \%)$ & $1(25 \%)$ & $1(11 \%)$ \\
\hline $\begin{array}{l}\text { Medicare and/or Private insurance offered through an employer, school } \\
\text { or union (self-insured or family plan) }\end{array}$ & $15(88 \%)$ & $3(75 \%)$ & $8(88 \%)$ \\
\hline \multicolumn{4}{|l|}{ Do you have other autoimmune diseases? } \\
\hline Yes & $13(76 \%)$ & $3(75 \%)$ & $0(0 \%)$ \\
\hline No & $4(24 \%)$ & $1(25 \%)$ & $9(100 \%)$ \\
\hline \multicolumn{4}{|c|}{ Who in the family was diagnosed with CD before attending Family Screening Day? } \\
\hline Child & $5(29 \%)$ & $0(0 \%)$ & $5(56 \%)$ \\
\hline Father & $1(6 \%)$ & $1(25 \%)$ & $0(0 \%)$ \\
\hline Mother & $5(29 \%)$ & $2(50 \%)$ & $1(11 \%)$ \\
\hline Mother \& Sibling & $1(6 \%)$ & $1(25 \%)$ & $0(0 \%)$ \\
\hline Sibling & $3(18 \%)$ & $0(0 \%)$ & $2(22 \%)$ \\
\hline Other ( 1 niece and nephew/1 cousin) & $2(12 \%)$ & $0(0 \%)$ & $1(11 \%)$ \\
\hline \multicolumn{4}{|l|}{ Do you see a healthcare provider regularly? } \\
\hline Yes & $16(94 \%)$ & $4(100 \%)$ & $8(89 \%)$ \\
\hline No & $1(6 \%)$ & $0(0 \%)$ & $1(11 \%)$ \\
\hline \multicolumn{4}{|l|}{ How often do you mention your family history of celiac disease? $n=16$} \\
\hline & & $\mathrm{n}=4$ & $\mathrm{n}=8$ \\
\hline Never & $2(12 \%)$ & $0(0 \%)$ & $2(25 \%)$ \\
\hline When provider inquiries about family history & $7(44 \%)$ & $0(0 \%)$ & $5(63 \%)$ \\
\hline Only once & $3(19 \%)$ & $1(25 \%)$ & $1(13 \%)$ \\
\hline At each appointment & $4(25 \%)$ & $3(75 \%)$ & $0(0 \%)$ \\
\hline \multicolumn{4}{|c|}{ What other health care providers do you see regularly? $(n=21$; some participants see more than 1 other provider) } \\
\hline None & $2(10 \%)$ & $2(50 \%)$ & $0(0 \%)$ \\
\hline Obstetrics/Gynecologist & $9(43 \%)$ & $2(50 \%)$ & $3(33 \%)$ \\
\hline Physician assistant & $2(10 \%)$ & $0(0 \%)$ & $1(11 \%)$ \\
\hline Nurse practitioner & $2(10 \%)$ & $0(0 \%)$ & $1(11 \%)$ \\
\hline Gastroenterologist & $2(10 \%)$ & $0(0 \%)$ & $1(11 \%)$ \\
\hline Other & $4(19 \%)$ & $0(0 \%)$ & $3(33 \%)$ \\
\hline
\end{tabular}

Among the 17 participants, in 2005 on Screening Day, 13 (77\%) tested negative and three (18\%) tested positive. One $(6 \%)$ did not remember their results. Among the three-testing positive, two went on to have a biopsy and subsequently initiated a gluten-free diet. One started the gluten-free diet without having a biopsy. Among the 13 who tested negative initially, four had been retested (31\%) and nine (69\%) had not been retested.

Most participants initially screened at Family Screening Day because they had a child (29\%) or a mother $(29 \%)$ who had CD. The relationship to the index CD patient differed between those who were initially negative and retested versus those who were initially negative and not retested. The mother was the index CD patient for $50 \%$ of the participants who were retested, compared to $11 \%$ of participants who did not get retested. The child was the index patient for $0 \%$ of the participants who were retested compared to $56 \%$ of participants who did not get retested.

Majority of the participants saw a healthcare provider regularly (94\%). However, there were differences in healthcare practices between those who initially tested negative and got retested, versus those who were not retested. All (100\%) of those who were retested saw a healthcare provider regularly, as compared to $89 \%$ of those who did not retest. Of the 16 participants who regularly saw a general healthcare provider, they also saw other healthcare providers such as a gynecologist. In the retested group, $50 \%$ of participants reported seeing an obstetrician/ gynecologist regularly as compared to $33 \%$ of the not retested group. Interestingly, the not retested participants reported seeing a greater 
diversity of healthcare providers including a nurse practitioner (11\%), physician's assistant (11\%), gastroenterologist (11\%), and others (33\%), compared to the retested group who reported only seeing their primary care or gynecologist.

In general, the degree to which participants disclosed their family history of $\mathrm{CD}$ to their healthcare provider varied. Thirteen percent of participants reported never discussing their family history of $\mathrm{CD}$, $19 \%$ only once, $25 \%$ at each appointment, and most (44\%) only when the provider inquired about family history. The discussion about and disclosure of family members with $\mathrm{CD}$ also differed between the two groups. Three-quarters of the retested participants mentioned their family history of $\mathrm{CD}$ at each appointment, while $63 \%$ of those who were not retested only mentioned their family history when the provider inquired about it.

There were several motivators and barriers for the decision to retest among those who initially tested negative at Family Screening Day (Table 2). The main response for not retesting were that participants reported they did not think they needed to get retested $(75 \%)$ or that they did not have symptoms (22\%). Those that retested, reported having multiple motivators including; symptoms (75\%), doctor $(50 \%)$ or family $(50 \%)$ recommendation, thinking they should be retested (50\%), or having an autoimmune disease $(75 \%)$.

\section{Discussion}

In this study, among the 13 participants who initially tested negative at Family Screening Day in 2005, less than a third (31\%) retested more than 14 years later. Interestingly, Faye and colleagues [18] reported a higher degree of testing of first-degree relatives (50\%) in general. However, in the Faye study, testing among symptomatic first-degree relatives remains below guideline recommendations in a celiac center population. In this study, we have found retesting rates to be even lower. These results highlight the importance of perceived motivators and barriers to retesting, as well as characteristics of those that retested.

Participants were more likely to be retested if they were the child of a parent diagnosed with CD. Perhaps this suggests that parents are particularly vigilant about getting their offspring tested subsequent to their own diagnosis. Participants were also more likely to be retested if they were female, had another autoimmune disease, had insurance, and had higher income. Inability to cover costs of testing if insurance does not pay may be an important deterrent to retesting.

In addition, our data suggests that participants were also more likely to be retested if they routinely saw a physician, an OB/GYN. The high use of the gynecologist compared to other healthcare providers could be due to the fact that celiac disease is more commonly diagnosed in females [9]. Additionally, in our population, the retested group were all female which may have influenced the use of OB/GYN over other health care providers. Nonetheless, OB/GYNs may be an important group of physicians to target future interventions that encourage celiac disease screening among their patients with a family history.

The use of health care providers amongst the retested versus the not retested groups warrants further investigation. It is curious that of the retested group, $50 \%$ saw only their primary care and the other $50 \%$ saw their OB/GYN in addition to their primary care physician. Of note, as stated before all the retested group were female. However, this does not explain the differences in health care provider use when compared to the not retested group. In the not retested group $(n=9)$ $44 \%$ were female and only $33 \%$ saw their OB/GYN in addition to their primary care physician. Further investigation needs to determine if the not retested group is seeking care from varied sources due to symptoms or if the rested group seeks less diverse care due to control of symptoms and disease state.

When asked about motivators to retesting, the primarily reasons were symptoms such as fatigue and bloating, as well as a physician or family recommendation. Of particular concern was that those who did not get retested were not aware that they should consider testing, despite the fact that seroconversion can occur in adulthood, and has been documented in family members [22]. These findings highlight the importance of physicians knowing the current guidelines that support repeat testing for first-degree family members with symptoms, as well as consideration for repeat testing for those without symptoms.

A strength of this study is that to our knowledge, this is the first study to survey family members of CD index patients to determine the motivators and barriers to retesting. The results of this study are limited by the small number of participants, a low response rate, perhaps not surprising after 14 years following a family screening event. As this was the initial follow up from a family screening, the survey tool has not been validated. Validating the survey as well as pursuing family members prospectively may provide additional information on motivators and barriers to testing. This study also relied on self-report and follow-up testing that was not confirmed with medical records. Data may also be subject to recall bias, given the length of time since the initial screening day.

\section{Conclusion}

Majority of the participants who tested negative after a family screening day did not have follow-up testing, primarily because they did not think follow-up testing was necessary, even in the presence of symptoms. In the light of the increased risk of CD in first-degree relatives, and the potential complications associated with undiagnosed and untreated CD, we suggest that testing guidelines should be shared amongst all healthcare providers to promote a greater degree of followup testing when appropriate.

\section{References}

1. Green PH, Jabri B (2003) Coeliac disease. Lancet 362: 383-391. [Crossref]

2. Gujral N, Freeman HJ, Thomson AB (2012) Celiac disease: prevalence, diagnosis, pathogenesis and treatment. World J Gastroenterol 18: 6036-6059. [Crossref]

3. Lo W, Sano K, Lebwohl B, Diamond B, Green PH (2003) Changing presentation of adult celiac disease. Dig Dis Sci 48: 395-398. [Crossref]

4. Green PH, Lebwohl B, Greywoode R (2015) Celiac disease. J Allergy Clin Immunol 135: 1099-1106. [Crossref]

5. Green PH, Cellier C (2007) Celiac disease. N Engl J Med 357: 1731-1743. [Crossref]

6. Dominguez Castro P, Harkin G, Hussey M, Christopher B, Kiat C, et al. (2017) Changes in Presentation of Celiac Disease in Ireland from the 1960s to 2015. Clin Gastroenterol Hepatol 15: 864-871.e3. [Crossref]

7. Kaukinen K, Partanen J, Mäki M, Collin P (2002) HLA-DQ typing in the diagnosis of celiac disease. Am J Gastroenterol 97: 695-699. [Crossref]

8. Bonamico M, Ferri M, Mariani P, Nenna R, Thanasi E, et al. (2006) Serologic and genetic markers of celiac disease: a sequential study in the screening of first-degree relatives. J Pediatr Gastroenterol Nutr 42: 150-154. [Crossref]

9. Rubio-Tapia A, Van Dyke CT, Lahr BD, Zinsmeister AR, El-Youssef M, et al (2008) Predictors of family risk for celiac disease: a population-based study. Clin Gastroenterol Hepatol 6: 983-987. [Crossef]

10. Singh P, Arora S, Lal S, Strand TA, Makharia GK (2015) Risk of Celiac Disease in the First- and Second-Degree Relatives of Patients with Celiac Disease: A Systematic Review and Meta-Analysis. Am J Gastroenterol 110: 1539-1548. [Crossref] 
11. Uenishi RH, Gandolfi L, Almeida LM, Fritsch PM, Almeida FC, et al. (2014) Screening for celiac disease in 1st degree relatives: a 10-year follow-up study. $B M C$ Gastroenterol 14: 36. [Crossref]

12. Peterson M, Grossman S (2016) Managing Celiac Disease for Women: Implications for the Primary Care Provider. Gastroenterol Nurs 39: 186-194. [Crossref]

13. Cavalli L, Guazzini A, Cianferotti L, Parri S, Cavalli T, et al. (2016) Prevalence of osteoporosis in the Italian population and main risk factors: results of Bone Tour Campaign. BMC Musculoskelet Disord 17: 396. [Crossref]

14. Rubio-Tapia A, Hill ID, Kelly CP, Calderwood AH, Murray JA, et al. (2013) ACG clinical guidelines: diagnosis and management of celiac disease. Am J Gastroenterol 108: 656-676, quiz 677. [Crossref]

15. AGA Institute (2006) AGA Institute Medical Position Statement on the Diagnosis and Management of Celiac Disease. AGA Institute. Gastroenterology 131: 1977-1780. [Crossref]

16. Hill ID, Fasano A, Guandalini S, Hoffenberg E, Levy J, et al. (2016) NASPGHAN Clinical Report on the Diagnosis and Treatment of Gluten-related Disorders. J Pediatr Gastroenterol Nutr 63: 156-165. [Crossref]
17. Roy A, Smith C, Daskalakis C, Voorhees K, Moleski S, et al. (2015) Physicians Caring for Celiac Patients do not Routinely Recommend Screening of First-Degree Family Members. J Gastroenterol Hepatol Res 4: 1838-1843. [Crossref]

18. Faye AS, Polubriaginof F, Green PHR, Vawdrey DK, Tatonetti N, et al. (2018) Low Rates of Screening for Celiac Disease Among Family Members. Clin Gastroenterol Hepatol 17: 463-468. [Crossref]

19. Horwitz A, Skaaby T, Kårhus LL, Schwarz P, Jørgensen T, et al. (2015) Screening for celiac disease in Danish adults. Scand J Gastroenterol 50: 824-831. [Crossref]

20. Mishra A, Prakash S, Kaur G, Sreenivas V, Ahuja V, et al. (2016) Prevalence of celiac disease among first-degree relatives of Indian celiac disease patients. Dig Liver Dis. 48: 255-259. [Crossref]

21. Bejares M, Oyarzún A, Lucero Y, Espinoza N, Bascuñán K, et al. (2015) Active search of celiac disease among first degree relatives of known celiac patients. Rev Med Chil 143: 1521-156. [Crossref]

22. Goldberg D, Kryszak D, Fasano A, Green PH (2007) Screening for celiac disease in family members: is follow-up testing necessary? Dig Dis Sci 52: 1082-1086. [Crossref]

Copyright: @2019 Lee AR. This is an open-access article distributed under the terms of the Creative Commons Attribution License, which permits unrestricted use, distribution, and reproduction in any medium, provided the original author and source are credited. 